\title{
Direct detection and quantification of malondialdehyde vapour in humid air using selected ion mass spectrometry supported by gas chromatography mass spectrometry
}

Violetta Shestivska ${ }^{1}$, Stefan S Antonowicz ${ }^{2}, K_{\text {Kseniya Dryahina }}{ }^{1}$, Jiří Kubišta ${ }^{1}$, David Smith ${ }^{3}$, Patrik Španěl ${ }^{1,3^{*}}$

${ }^{1}$ J. Heyrovsky Institute of Physical Chemistry of Science, Academy of Science of the Czech Republic, Dolejškova 3, 18223 Prague 8, Czech Republic

${ }^{2}$ Department of Surgery and Cancer, Imperial College London, St. Mary's Hospital, Praed Street, London, W2 1NY, UK

${ }^{3}$ Institute for Science and Technology in Medicine, School of Medicine, Keele University, Thornburrow Drive, Hartshill, Stoke-on-Trent ST4 7QB, UK

\begin{abstract}
RATIONALE:

It has been proposed that malondialdehyde (MDA) reflects free oxygen-radical lipid peroxidation and can be useful as a biomarker to track this process. For the analysis of MDA molecules in humid air by selected ion flow tube mass spectrometry (SIFT-MS), the rate coefficients and the ion product distributions for the reactions of the SIFT-MS reagent ions with volatile MDA in the presence of water vapour are required.
\end{abstract}

\section{METHODS:}

The SIFT technique has been used to determine the rate coefficients and ion product distributions for the reaction of $\mathrm{H}_{3} \mathrm{O}^{+}, \mathrm{NO}^{+}$and $\mathrm{O}_{2}{ }^{+\bullet}$ with gas phase MDA. Then, in support of SIFT-MS analysis of MDA, solid phase microextraction, SPME, coupled with gas chromatography mass spectrometry, GC/MS, has been used to confirm MDA identification.

\section{RESULTS:}

The primary product ions have been identified for the reactions of $\mathrm{H}_{3} \mathrm{O}^{+}, \mathrm{NO}^{+}$and $\mathrm{O}_{2}{ }^{+\bullet}$ with MDA and the formation of their hydrates formed in humid samples is described. Thus, the following combinations of reagent and the analyte ions (given as $\mathrm{m} / \mathrm{z}$ values) are adopted for SIFT-MS analyses of MDA in the gas phase: $\mathrm{H}_{3} \mathrm{O}^{+}: 109 ; \mathrm{NO}^{+}: 89,102 ; \mathrm{O}_{2}{ }^{+\bullet}: 72,90,108,126$. The detection and quantification of MDA released by a cell culture by SIFT-MS is demonstrated.

\section{CONCLUSIONS:}

This detailed study has provided the kinetics data required for the SIFT-MS analysis of MDA in humid air, including exhaled breath and the headspace of liquid phase biogenic media. Consequently, the quantification of MDA in humid gaseous media can now be used to assess oxidative stress in biogenic systems.

* Correspondence to: P. Španěl, J. Heyrovsky Institute of Physical Chemistry, Academy of Science of the Czech Republic, Dolejškova 3, 18223 Prague 8, Czech Republic.

E-mail: spanel@jh-inst.cas.cz 
Malondialdehyde (MDA) is a frequently used indicator of free oxygen-radical-induced lipid peroxidation. Thus, MDA monitoring is of interest in all diseases in which the molecular aetiology increases 'oxidative stress', including (but by no means limited to) atherosclerosis, diabetes, liver disorders, cancer, autoimmune and neurogenerative disease ${ }^{[1,2]}[\underline{[3-6]}$. Most usually, MDA is assayed in liquid state serum, plasma, urine, saliva and other biological samples by colorimetric and fluorimetric techniques ${ }^{\left[{ }^{7]}\right.}$. As far as we are aware, the direct quantification of MDA molecules in the gas phase has not been achieved, but should this be possible, it could be a valuable target compound and a non-invasive biomarker via headspace studies of biogenic fluids and in breath analysis for bacterial lung infection or even lung cancer. However, the high reactivity and instability of MDA [6] might inhibit its use as a gas phase biomarker. Given our recent focus on the exploitation of SIFT-MS analysis of exhaled breath ${ }^{[8-11]}$ and headspace of mammalian and bacterial cell cultures ${ }^{[12-15]}$ when MDA has often been mentioned, we now feel constrained to investigate the potentially rewarding prospect of gas phase MDA analysis. Thus, in the present study we describe a method for the accurate real-time quantification of gas phase MDA using selected ion flow tube mass spectrometry (SIFT-MS) supported by solid phase microextraction coupled with gas chromatography mass spectrometry (SPME/GC/MS) for compound confirmation. This study follows similar focused kinetics studies of the ion chemistry of $\mathrm{H}_{2} \mathrm{CO}{ }^{[16]}, \mathrm{H}_{2} \mathrm{~S}{ }^{[17]}, \mathrm{HCN}{ }^{[18]}, \mathrm{CH}_{4}{ }^{[19]}$ and $\mathrm{C}_{5} \mathrm{H}_{12}{ }^{[10]}$ as reported previously in Rapid Comm. Mass Spec., which were required to achieve analysis of these compounds in humid air by SIFTMS.

\section{Background MDA chemistry}

MDA (see Scheme 1) is one of many aldehydes that are produced during the peroxidative decomposition of unsaturated fatty acids ${ }^{[20]}$. Compared to free radicals, most aldehydes are quite stable, diffuse from cells and attack targets far from their site of their production. About 32 aldehydes have been identified as products of lipid peroxidation ${ }^{[21]}$ including saturated aldehydes (propanal, butanal, hexanal, octanal and decanal), 2,3-trans-unsaturated-aldehydes (hexenal, octenal, nonenal, decenal and undecenal) and a series of 4-hydroxy-2,3-trans-unsaturated aldehydes (4-hydroxyundecenal and 4-hydroxinonenal). MDA has been considered for some time to be the most important lipid peroxidation metabolite [21].

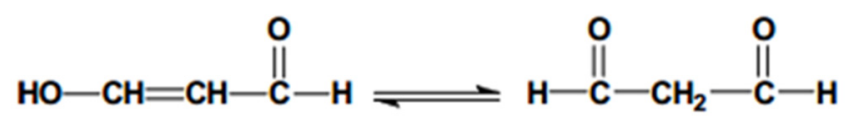

Scheme 1. Two structural forms of malondialdehyde with molecular formula $\mathrm{C}_{3} \mathrm{H}_{4} \mathrm{O}_{2}$ and relative molar mass $72.07 \mathrm{~g} / \mathrm{mol}$.

Pure MDA is a solid with melting point of $72-74^{\circ} \mathrm{C}$. It is known to be relatively stable in $\mathrm{pH}$ neutral solutions but unstable under acidic conditions. Under physiological conditions ( $\mathrm{pH}$ 5-7) it is presumed to be present in the form of a much less reactive conjugate base $\left[{ }^{-} \mathrm{O}-\mathrm{CH}=\mathrm{CH}-\right.$ CHO] ${ }^{[22]}$. MDA can interact with many biological molecules including lipoproteins, peptides and DNA, altering their chemical behaviour ${ }^{[21]}$, which has attracted much attention in different 
research areas. Its high reactivity is based on its electrophilicity that makes it strongly reactive toward cellular compartments and lipid cell membranes. It has been detected in many animal and vegetable foodstuffs and plants and is found in human and animal tissue as an end-product of lipid peroxidation.

\section{Current methods used for MDA quantification}

Several methods are currently used to identify and quantify MDA in biological fluids, including spectrophotometry and fluorimetric detection, high performance liquid chromatography (HPLC), gas chromatography (GC) and immunological techniques ${ }^{[5]}$. The most common method for MDA analyses is based on the reaction with 2-thiobarbituric acid (TBA) in acidic media at $100{ }^{\circ} \mathrm{C}$ forming the MDA-TBA complex that can be quantified by spectrophotometry or fluorimetry [7]. In spite of their simplicity and low cost, such analyses have received wide criticism over the years. The main problem is the lack of sensitivity and specificity, since TBA reacts with a variety of compounds (so called TBA reactive species, TBARS), including other aldehydes, sugars, amino acids, bilirubin and albumin ${ }^{[21]}$. The results of TBARS analyses, even though often quoted in the units of MDA concentration (for example $\mu \mathrm{mol} / \mathrm{L}$ ), do not necessarily indicate the presence of MDA. Selective extraction of MDA molecules from biological samples is difficult because they are small, polar, relatively unstable and highly water-soluble [23]. Therefore, analytical derivatization is commonly employed to stabilise the MDA molecules and also increase their volatility. Both HPLC ${ }^{[24]}$ and GC have been used ${ }^{[25-27]}$ that demonstrated this approach to be more specific than the widely used TBARS ${ }^{[7]}$. The use of TBARS and HPLC in combination has been also reported [28]. Especially interesting to the subject of biomarker detection are the recent HPLC studies of MDA in exhaled breath condensate [29, 30]. Also relevant are the GC analyses of derivatised MDA in blood headspace using solid phase microextraction (SPME) ${ }^{[31]}$.

\section{Rationale for the present study}

There is a growing interest in non-invasive monitoring of lipid peroxidation processes by analyses of volatile organic compounds in the headspace of biological samples or in exhaled breath. Volatile hydrocarbons resulting from polyunsaturated fatty acids oxidation have been studied previously in this context $[10,32]$. Several aldehydes resulting from peroxidative processes have also been studied in the gas phase using SIFT-MS and GC/MS ${ }^{[33}$, 34$]$. A detailed SIFT-MS investigation of head space aldehydes as biomarkers of peroxide oxidation processes has been carried out by B. Ross and co-authors [35]. This study involved SIFT-MS quantification of 18 saturated volatile aldehydes however, MDA was not included. The promising volatile biomarker of lipid peroxidation MDA has so far only been quantified in headspace after its derivatization [31]. For the analysis of MDA molecules in humid air by selected ion flow tube mass spectrometry (SIFT-MS), the rate coefficients and the product ion distributions for the reactions of the SIFT-MS reagent ions with gas phase MDA molecules in the presence of water vapour are required and this need is the prime motivation for the present study. 


\section{Experimental}

As a first step, a selected ion flow tube, SIFT, study was performed of the reaction of $\mathrm{H}_{3} \mathrm{O}^{+}, \mathrm{NO}^{+}$ and $\mathrm{O}_{2}{ }^{+\bullet}$ precursor ions with MDA molecules in order to establish the primary product ions of the reactions and hence to identify appropriate analyte ions for the analysis of MDA by SIFTMS. To achieve this, the rate coefficients for the analytical reactions are also required, but, as we will explain, it was not possible to determine these experimentally, so theory has to be invoked. Inevitably, secondary reactions of the primary product ions of the reactions with water molecules occur when analysing humid mixtures, so these reactions were also studied in order to identify which hydrate ions must be included as additional analyte ions in the SIFT-MS kinetics library in order to achieve accurate analyses of MDA in humid air ${ }^{[36-39]}$. The collected kinetic data were then used to formulate the appropriate kinetics library entries $[\underline{36}, \underline{40]}$. Additional to these SIFT studies it was considered important to perform the GC/MS experiments described below in order to corroborate the SIFT mass spectrometric identification of the synthesised MDA that was used in all these experiments. Finally, pilot real-time analyses of MDA formed via lipid peroxidation were carried out to test the efficacy of detection and analysis of MDA by SIFT-MS.

\section{Selected ion flow tube, SIFT, determination of product ion branching ratios}

The SIFT technique has been described in detail for the determination of the rate constants and ion product distributions of ion-molecule reactions, including many reactions of $\mathrm{H}_{3} \mathrm{O}^{+}, \mathrm{NO}^{+}$and $\mathrm{O}_{2}{ }^{+\bullet}$ with many classes of organic compounds $\left[10, \underline{16-19}, \underline{38}, \underline{41}, \underline{42]}\right.$. Ion swarms ${ }^{[43]}$ of $\mathrm{H}_{3} \mathrm{O}^{+}, \mathrm{NO}^{+}$ and $\mathrm{O}_{2}{ }^{+\bullet}$ precursors are formed by injecting mass filtered ions into He carrier gas. Then, in the present experiments, the headspace of an aqueous solution containing a trace amount (typically less than $10 \mathrm{ppmv}$ ) of MDA vapour, prepared as described below, was introduced into the SIFT instrument (Profile 3 SIFT-MS manufactured by Instrument Science Limited, Crewe, UK) via a heated calibrated capillary and full scan (FS) mass spectra comprising the precursor ions and the product ions and any of their hydrates were acquired. The $m / z$ mass spectral range covered was chosen as 10-180 that was wide enough to encompass all the primary product ions and their hydrates. For each precursor ion species, five full mass spectra (FS) were obtained with a total integration time of $60 \mathrm{~s}$, as exemplified later. The major ion products were identified and their count rates were precisely determined in separate experiments using the multi-ion monitoring (MIM) mode of SIFT and SIFT-MS [42]. In order to determine the primary product branching ratios of the reactions, the percentages of the individual product ions were plotted on a linear scale as a function of the sample mixture flow rate, as described previously [ $\underline{38}, \underline{41}]$ and exemplified later.

\section{Preparation of the MDA solution}

Pure MDA is an unstable aldehyde that cannot be easily stored and shipped. Thus, for the purposes of these experiments, it was necessary to synthesize the MDA, and this was done by diluting $10 \mu \mathrm{L}$ of 1,1,3,3-Tetraethoxypropane (TEP) with $10 \mathrm{~mL}$ of $0.1 \mathrm{M} \mathrm{HCl}$ solution, this mixture then being incubated at $100^{\circ} \mathrm{C}$ for $10 \mathrm{~min}$ to hydrolyse the TEP to MDA [27]. Thus, a standard solution of MDA at a concentration of $300 \mathrm{mg} \mathrm{L}^{-1}$ was obtained. Ethanol is a byproduct of this synthesis and appears in the solution headspace at concentrations that can 
interfere with SIFT and SIFT-MS measurements. Fortunately, its concentration can be minimised by judicious choice of the $\mathrm{TEP} / \mathrm{HCl}$ ratio and by partial venting to reduce the solution/headspace ethanol concentration. As can be seen later in the SIFT-MS spectra, the ethanol headspace concentration is reduced to acceptably low levels by these procedures. The chemicals and reagents used were purchased from Sigma Aldrich spol. s r.o. (Sokolovská 100/94 Praha 8).

The headspace of this solution was used both as the sample air/vapour mixture for the SIFT studies and for the SPME/GC/MS extraction/pre-concentration studies. Additional GC/MS studies involved the commonly used derivatization method. Thus, the MDA was derivatized by pentaphluorophenylhydrazine (PFPH) during $10 \mathrm{~min}$ of incubation time at $70^{\circ} \mathrm{C}$ in $15 \mathrm{~mL}$ vials closed with septa in which $5 \mathrm{~mL}$ of MDA solution or sample was mixed with $1 \mathrm{mg}$ of PFPH (powder 99\%) ${ }^{[27]}$. Then the volatile MDA derivative was adsorbed from the headspace using an SPME fibre and injected into the GC/MS instrument in the usual way.

\section{Cancer cell culture}

Lung adenocarcinoma cancer cells (A549) in culture are used as a model for the pilot test of the developed real-time SIFT-MS quantification method. STR-validated A549 cells were cultured according to ATCC (Manassas, Virginia) recommendations in the RPMI-1640 medium (developed by Moore et. al. at Roswell Park Memorial Institute, Buffalo NY ${ }^{[44]}$ ) supplemented with 10\% heat-inactivated foetal calf serum (FCS), $2 \mathrm{mM}$ glutamine, and $1 \%$ penicillin/streptomycin. The confluence (fraction of surface area covered by cells) was $80 \%$.

\section{SPME/GC/MS sampling and analysis protocol}

The volatile organic compounds (VOCs) were extracted from the headspace of the standard MDA mixture along with the MDA-PFPH derivative using carboxene polydimethylsiloxane (CAR/PDMS)-coated SPME fibres (Supelco, Bellefonte, PA, USA) for a period of $15 \mathrm{~min}$ at a temperature of $37^{\circ} \mathrm{C}$. Then the fibres were directly inserted into an injector of the GC/MS instrument (FOCUS GC with split/splitless injector (SSL), ITQ 700 ion trap mass spectrometer using electron ionisation, Thermo Fisher Scientific Inc., USA ) held at $220^{\circ} \mathrm{C}$. A GC/MS capillary column TG-624 (fused 100\% cyanopropylphenyl polysiloxane, $30 \mathrm{~m}$ x $0.25 \mathrm{~mm}$ ID x $1.0 \mathrm{um}$ film., Thermo Fisher Scientific Inc., USA) was used under the following conditions: splitless injection, helium carrier gas flow of $1 \mathrm{~mL} / \mathrm{min}$, temperature program $38^{\circ} \mathrm{C}$ (hold $3 \mathrm{~min}$ ) $20^{\circ} \mathrm{C} / \mathrm{min}$ ramp up to $220^{\circ} \mathrm{C}$ (hold $3 \mathrm{~min}$ ). The total run time was $15 \mathrm{~min}$. Electrons at energy of $70 \mathrm{eV}$ were used to generate ions which were analysed by the ion trap operating in the scan mode $(\mathrm{m} / z-15-400$, scan rate $1 \mathrm{scan} / \mathrm{s})$.

\section{Results and discussion}

The structure of this section is as follows: firstly, the results of the ion chemistry studies i.e. the experimentally determined ion products and the calculated rate coefficients for the reactions of $\mathrm{H}_{3} \mathrm{O}^{+}, \mathrm{NO}^{+}$and $\mathrm{O}_{2}{ }^{+\bullet}$ with MDA molecules in the presence of water molecules are given. Then a short section indicates the appropriate entries to the SIFT-MS kinetics library that are required

for MDA analysis. This is followed by a brief section describing the SPME/GC/MS experiments 
that verifies the identification of MDA. Finally, an example is given of the production and detection of MDA by an in vitro cell culture subjected to peroxidative stress, which shows that SIFT-MS can track the production of MDA in biological systems.

Reaction of $\mathrm{H}_{3} \mathrm{O}^{+}$with $\mathrm{MDA}$.

A SIFT spectrum obtained using $\mathrm{H}_{3} \mathrm{O}^{+}$precursor ions when the headspace of the MDA solution (1,1,3,3-Tetraethoxypropane (TEP) with $0.1 \mathrm{M} \mathrm{HCl,} \mathrm{Sigma} \mathrm{Aldrich} \mathrm{spol.} \mathrm{s} \mathrm{r.o.} \mathrm{Sokolovská}$ 100/94 18600 Praha 8) is introduced into the helium carrier gas is shown in Fig. 1, plotted as the $\log$ of the ion count rate, c/s, against the mass-to-charge ratio, $m / z$, of the ions. Immediately obvious are the majority $\mathrm{H}_{3} \mathrm{O}^{+}\left(\mathrm{m} / z\right.$ 19) and its hydrates $\mathrm{H}_{3} \mathrm{O}^{+}\left(\mathrm{H}_{2} \mathrm{O}\right)_{1,2,3}$ at $\mathrm{m} / z$ values of 37,55 , 73 and much smaller ion peaks at $\mathrm{m} / z 91$ and 109 that could be designated as the higher-order $\mathrm{H}_{3} \mathrm{O}^{+}\left(\mathrm{H}_{2} \mathrm{O}\right)_{4,5}$ hydrates. However, very significantly, the nominal molecular mass of MDA $\left(\mathrm{C}_{3} \mathrm{H}_{4} \mathrm{O}_{2}\right)$ is 72 Daltons and because of the high proton affinity of aldehydes ${ }^{[39]}$ it is confidently expected that the MDA molecule will accept a proton from $\mathrm{H}_{3} \mathrm{O}^{+}$on every $\mathrm{H}_{3} \mathrm{O}^{+} / \mathrm{MDA}$ collision to produce $\mathrm{MDAH}^{+}$ions also at $m / z$ 73. These $\mathrm{MDAH}^{+}$ions will efficiently hydrate to produce $\mathrm{MDAH}^{+}\left(\mathrm{H}_{2} \mathrm{O}\right)_{1,2}$ ions at $m / z 91$ and 109. So the overlap of the $m / z 73$ ions precludes the use of $\mathrm{MDAH}^{+}$as an analyte ion for MDA analysis by SIFT-MS as does the ions at $m / z 91$, because the $\mathrm{H}_{3} \mathrm{O}^{+}\left(\mathrm{H}_{2} \mathrm{O}\right)_{4}$ ions are relatively abundant product ions when humid samples are being analysed. Fortunately, $\mathrm{H}_{3} \mathrm{O}^{+}\left(\mathrm{H}_{2} \mathrm{O}\right)_{5}$ production is inefficient and thus $m / z 109$ ions can be used as an analyte ion for MDA analysis. However, the relative fraction of $\operatorname{MDAH}^{+}\left(\mathrm{H}_{2} \mathrm{O}\right)_{2}$ in the total analyte ions needs to be known and, even then, only an approximate quantification of MDA can be obtained. Because of these problems, further consideration of $\mathrm{H}_{3} \mathrm{O}^{+}$as a reagent ion for SIFTMS analysis of MDA is not given here and attention is now given to the more suitable $\mathrm{NO}^{+}$and $\mathrm{O}_{2}{ }^{+\bullet}$ reagent ions. Note in the spectrum of Fig. 1 that the peak levels of the characteristic product ions of the $\mathrm{H}_{3} \mathrm{O}^{+}$/ethanol reaction at $m / z$ values of 47,65 and 83 are relatively small.

\section{Reaction of $\mathrm{NO}^{+}$with $\mathrm{MDA}$}

A SIFT spectrum obtained using $\mathrm{NO}^{+}$precursor ions when the headspace of the MDA solution is introduced into the helium carrier gas is shown in Fig. 2, as usual plotted as the log c/s, against $m / z$. Immediately obvious are the majority $\mathrm{NO}^{+}$ions at $m / z 30$ and its hydrates $\mathrm{NO}^{+}\left(\mathrm{H}_{2} \mathrm{O}\right)_{1,2}$ at $\mathrm{m} / \mathrm{z} 48$ and 66 . The primary product ion at $\mathrm{m} / \mathrm{z}$ of 71 is the result of the hydride ion extraction reaction between $\mathrm{NO}^{+}$and $\mathrm{C}_{3} \mathrm{H}_{4} \mathrm{O}_{2}$ (MDA) resulting in $\mathrm{C}_{3} \mathrm{H}_{3} \mathrm{O}_{2}{ }^{+}$; this ion partially hydrates to its monohydrate $\mathrm{C}_{3} \mathrm{H}_{3} \mathrm{O}_{2}{ }^{+} \mathrm{H}_{2} \mathrm{O}$ at $m / z$ 89. The product ion at $m / z 102$ is the adduct ion $\mathrm{NO}^{+} \mathrm{C}_{3} \mathrm{H}_{4} \mathrm{O}_{2}$ also formed in primary reaction and that at $m / z 120$ is its monohydrate $\mathrm{NO}^{+} \mathrm{C}_{3} \mathrm{H}_{4} \mathrm{O}_{2} \cdot \mathrm{H}_{2} \mathrm{O}$. Parallel hydride ion transfer and adduct formation is not uncommon in the reactions of $\mathrm{NO}^{+}$with aldehydes, especially so for unsaturated aldehydes $[\underline{34}, \underline{39}, \underline{45}]$.

It is clear from these data that $\mathrm{NO}^{+}$reagent ions are a much better prospect for the quantification of MDA by SIFT-MS. So in order to determine how the relative signal levels of the four product ions at $m / z 71,89,102$ and 120 vary with sample humidity the standard approach to branching ratio variations has been taken in which the signal levels $(\mathrm{c} / \mathrm{s})$ of these ions are measured whilst introducing the humid headspace of the standard solutions of MDA at varying flow rate into the 
helium carrier gas of the instrument. The humidity of the sample headspace was varied by raising its temperature in a controlled way, and since the sample flow is only a small fraction of the helium carrier gas flow, the increase in temperature of the helium/sample mixture is insignificant. The humidity is determined from the relative signal levels of the precursor ion hydrates, as is the routine procedure in SIFT-MS [36, 46]. Sample data are shown in Fig.3 revealing that the count rate of the major primary product ion at $\mathrm{m} / \mathrm{z} 71$ decreases rapidly with increasing humidity until at $6 \%$ humidity (corresponding to the saturated water vapour pressure at body temperature of 37C). The hydrate at $\mathrm{m} / \mathrm{z} 89$ becomes comparable in magnitude to the ion at $\mathrm{m} / \mathrm{z}$ 71 under these SIFT (and SIFT-MS) conditions. The adduct ion at $\mathrm{m} / \mathrm{z} 102$ is never greater than about $20 \%$ of the total product ion signal, and its hydrate at $\mathrm{m} / \mathrm{z} 120$ is not more than about $5 \%$.

\section{Reaction of $\mathrm{O}_{2}^{+\bullet}$ with $\mathrm{MDA}$}

A SIFT spectrum obtained using $\mathrm{O}_{2}{ }^{+*}$ precursor ions when the headspace of the MDA solution is introduced into the helium carrier gas is shown in Fig. 4, again plotted as the $\log \mathrm{c} / \mathrm{s}$, against $\mathrm{m} / \mathrm{z}$. Immediately obvious are the majority $\mathrm{O}_{2}{ }^{+\bullet}$ ions $(m / z ~ 32)$ and the $\mathrm{H}_{3} \mathrm{O}^{+}\left(\mathrm{H}_{2} \mathrm{O}\right)_{0,1,2,3}$ ions at $m / z$, 37,55 and 73 that are always seen and are formed in the complex ion chemistry of $\mathrm{O}_{2}{ }^{+\cdot}$ with water molecules ${ }^{[47]}$ (in contrast, see the relative signal levels of these ions in Fig. 1). The very small signal at $\mathrm{m} / \mathrm{z} 50$ is the monohydrate of the $\mathrm{O}_{2}{ }^{+\bullet}$. The clearly identifiable product ion originating from MDA are those at $m / z$ 72, 90, 108 and 126, but this ion chemistry is complicated and multiple smaller product ions are seen at $\mathrm{m} / \mathrm{z} 43$ and 71 that are the result of fragmentation in the relatively energetic charge transfer occurring in the reaction $\mathrm{of}_{2}{ }^{+\bullet}$ with MDA molecules; this fragmentation process is quite common in the reactions of $\mathrm{O}_{2}{ }^{+\bullet}$ with polyatomic molecules $[38,42]$. For the moment, we choose to exclude these minor fragment ions and, as for the $\mathrm{NO}^{+}$reaction, the signal levels of the aforementioned four product ions were measured as a function of the sample gas humidity. Sample data are shown in Figure 5 revealing that the count rate of the major parent cation $\mathrm{MDA}^{+}$at $\mathrm{m} / \mathrm{z} 72$ decreases rapidly with increasing humidity until at $6 \%$ humidity its hydrates $\operatorname{MDA}^{+}\left(\mathrm{H}_{2} \mathrm{O}\right)_{2,3}$ at $\mathrm{m} / z 108$ and 126 becomes comparable to its magnitude under these SIFT (and SIFT-MS) conditions. Curiously, the monohydrate at $\mathrm{m} / \mathrm{z} 90$ is always a small fraction of the total ion signal; what is remarkable and unusual is the rapidity of the hydration to the dihydrate and trihydrate ions, which may be a feature of molecules containing both $-\mathrm{OH}$ and $-\mathrm{CHO}$ groups, but the gas phase reactions of such molecules with ions have rarely been studied.

\section{Construction of kinetics library entries for the analysis of MDA by SIFT-MS}

The prime objective of the above ion chemistry study was to identify the most suitable reagent ion species with which to quantify MDA in the gas phase and to detect and quantify MDA in the humid air that is the headspace above biological fluids. The following are the $m / z$ values of the major product ions for the reactions of $\mathrm{H}_{3} \mathrm{O}^{+}, \mathrm{NO}^{+}$and $\mathrm{O}_{2}{ }^{+\bullet}$ with MDA molecules, those given in bold being potential analyte ions for SIFT-MS analysis of MDA:

$\mathrm{H}_{3} \mathrm{O}^{+} ; 73,91, \mathbf{1 0 9}: \mathrm{NO}^{+} ; \mathbf{7 1}, \mathbf{8 9}, \mathbf{1 0 2}, \mathbf{1 2 0}: \mathrm{O}_{2}{ }^{+\bullet} ; 43,71, \mathbf{7 2}, \mathbf{9 0}, \mathbf{1 0 8}, 126$ 
The rationale behind the inclusions/exclusions as analyte ions of any of these product ions for each reagent ion is given in the previous sections. Excluding any of the product ions requires that their fractions of the total product ions must be accounted for when constructing the kinetics library entries for SIFT-MS analyses [36, 40]. This is done by applying a multiplication factor (greater than unity) to those product ions included as analyte ions, as can be seen in the constructed kinetics library entry shown in Table 1; this is elaborated upon below. These multiplication factors are obtained from data such as those shown in Figures 3 and 5 by optimising the results of calculations of MDA concentrations so that they are constant across the entire range of humidity.

For accurate SIFT-MS analyses, rate coefficients for the analytical reactions must also be entered into the kinetics library. Experimental difficulties often preclude their measurement, usually because the preparation of gaseous mixtures of volatile organic compounds at accurately known concentrations is difficult. Such is especially so for the unstable MDA. Under such circumstances, the only approach is to rely on theory to calculate the collisional rate coefficients. Fortunately, it has often been shown that when proton transfer from an ion to a molecule is exothermic (by more than $25 \mathrm{~kJ} / \mathrm{mol}$ ) then it occurs on every collision, i.e. at the collisional or gas kinetic rate ${ }^{[48]}$. Because the proton affinity of all aldehyde molecules exceeds that of the water molecule ${ }^{[49]}$ then proton transfer is facile from $\mathrm{H}_{3} \mathrm{O}^{+}$to MDA and the collisional rate coefficient can be calculated by the theory of $\mathrm{Su}$ and Chesnavich [50]. The collisional rate coefficients are calculated ab-initio using the DFT B3LYP method (NWChem software version 6.5, Pacific Northwest National Laboratory, Richland, Washington, US) using a dipole moment of $4.8 \mathrm{D}$, and a polarizability of $6 \AA^{2}$ calculated according Miller and Savchik ${ }^{[\underline{51}]}$ are given in Table 1. However, it cannot be tacitly assumed that the reactions of $\mathrm{NO}^{+}$and $\mathrm{O}_{2}{ }^{+\bullet}$ with MDA proceed at their collisional rates, but it is often possible to perform SIFT experiments in which the loss rates of these two ion species can be compared to that of $\mathrm{H}_{3} \mathrm{O}^{+}$from which data the rate coefficients for the $\mathrm{NO}^{+}$and $\mathrm{O}_{2}{ }^{+\bullet}$ can be deduced. But such experiments require that sufficient flows of the organic vapour, in this case MDA, can be introduced into the helium carrier gas to significantly reduce the signals of the reactant precursor ions ${ }^{[41]}$. Unfortunately, this could not be achieved because the production process for MDA adopted in these experiments could not realise high enough concentrations of pure MDA in the liquid headspace. Nevertheless, many studies in many laboratories have shown that the reactions of $\mathrm{NO}^{+}$and $\mathrm{O}_{2}{ }^{+\bullet}$ with aldehydes and most other polyatomic molecules do proceed at or very close to their respective collisional rates and so it is acceptable to use the aforementioned collisional theory to calculate appropriate rate coefficients for their reactions with MDA. Thus, the calculated rate coefficients for the reactions of $\mathrm{H}_{3} \mathrm{O}^{+}, \mathrm{NO}^{+}$and $\mathrm{O}_{2}{ }^{+\cdot}$ with MDA molecules and those of the hydrates $\mathrm{H}_{3} \mathrm{O}^{+}\left(\mathrm{H}_{2} \mathrm{O}\right)_{1,2,3}$ and $\mathrm{NO}^{+}\left(\mathrm{H}_{2} \mathrm{O}\right)_{1,2}$, which must be included as reagent ions for accurate SIFT-MS analyses. $\stackrel{36,}{37}, \underline{40}$, are adopted in the kinetics library entries. These are given in Table 1 for the analysis by SIFTMS of MDA in samples at $6 \%$ absolute humidity using the three reagent ions. Further discussion of the construction of these kinetics library entries in the format used in Profile 3 SIFT-MS software is given in recent papers $[\underline{36}, \underline{38}]$.

GC/MS verification of $M D A$ synthesis 
The ion chemistry studies described above, in particular the ion products of the $\mathrm{NO}^{+}$reaction that conform to the expectations for the reaction of $\mathrm{NO}^{+}$with aldehydes [34, 39, 45, $\underline{52}$, confirmed the identity of the synthesized molecule as MDA. To our knowledge, direct gas phase detection and analysis of MDA molecules has not been carried out previously; thus, we felt constrained to reinforce and verify the presence of MDA.

The detection of MDA by preparing a derivative using pentafluorophenylhydrazine (PFPH) to form the stable volatile adduct $N$-pentafluorophenylpyrazole followed by extraction of the derivative from the headspace using SPME followed by GC/MS analysis is well established [2527]. The structure of MDA-PFPH derivative is shown in Fig. 6. Its electron ionisation (EI) fragmentation pattern is known [27], the major ion being its molecular ion at $m / z 234$ with other minor fragment ions at $m / z 117,167,180,194$ and 207. So, following this precedent, we used PFPH to prepare the derivative of the assumed MDA in the standard water solution, $(300 \mathrm{mg} / \mathrm{L})$ as used for the ion chemistry studies, and used SPME/GC/MS for its analysis.

Fig. 6 shows the limited SPME/GC-MS chromatogram indicating a retention time for the MDAPFPH derivative of 12.17 minutes in the GC column used (TG-624 fused $100 \%$ cyanopropylphenyl polysiloxane). The EI mass spectrum obtained for this eluted compound is also shown in Fig. 6 where it can be seen that the $m / z$ values of the peaks $(\mathrm{m} / z 234$ for the molecular radical cation and fragments at 117,167,180, 194 and 207) conform to those given above and thus correspond to the known mass spectrum from previous works ${ }^{[27]}$. This we take as confirmation that the synthesized molecule is indeed MDA. It is interesting to note that a clear peak appeared in the wider GC chromatogram at a retention time of 5.60 minutes. This we postulate to be underivatized MDA molecules, but the EI spectrum for MDA is not included in the GC/MS database and is presumably unknown. So we performed this SPME/GC/MS experiment again, confirmed an elution time of 5.60 minutes and thus obtained the $70 \mathrm{eV}$ MS fragmentation spectrum for MDA, as is shown in Figure 7. As far as we know, the EI mass spectrum of MDA has not been given in any NIST database and has not been published previously. The parent molecular ion $\mathrm{MDA}^{+}$at $m / z 72$ is obvious, but the major fragment ion is at $m / z 71$ that results from loss of an $\mathrm{H}$ atom from the nascent excited $\left(\mathrm{MDA}^{+}\right)^{*}$. The minor ion at $m / z 54$ may results from loss of a water molecule [MDA- $\left.\mathrm{H}_{2} \mathrm{O}\right]^{+}$and the ion at $\mathrm{m} / z 43$ probably result from the loss of an HCO moiety as is typical of EI fragmentation of aldehydes. This study clearly demonstrates that the direct detection of MDA in the gas phase has been achieved and it can be quantified using SIFT-M

\section{SIFT-MS quantification of MDA in the headspace of a model biological fluid}

To test the claim stated in the last sentence of the previous section, we carried out the following experiment. Lung adenocarcinoma cancer cells (A549) (of particular interest to a member of the team (S.S.A) and the Imperial College London Oncology Group ${ }^{[53]}$ ) were cultured in serum medium. Hydrogen peroxide $\left(\mathrm{H}_{2} \mathrm{O}_{2}\right)$ was then added at a lethal concentration $(20 \mathrm{mM})$ to initiate peroxidation stress, which is expected to generate MDA ${ }^{[54-56]}$. Direct and continuous SIFT-MS analysis of the headspace was performed for a few minutes, beginning immediately after the 
addition of the $\mathrm{H}_{2} \mathrm{O}_{2}$, using $\mathrm{NO}^{+}$reagent ions and the analyte ions at $m / z$ values of $71,89,102$ and 120. Due to overlaps with other headspace compounds only $m / z 89$ and 102 were included for quantification (see Table 1). The results obtained are given in Fig. 8 which show that the count rates of all four analyte ions increased to peak values after a time of about 8 minutes (Fig. $8 \mathrm{a}$ ), thus reflecting the MDA concentration which increased for about 8 minutes and then began to decrease. The limit of detection, as calculated from the count rates of the product ions ${ }^{[40]}$, was 0.3 parts-per-billion by volume, ppbv, and the precision of quantification was \pm 3 ppbv. These data indicate that either MDA production slows down due to cell membrane destruction and death or that the MDA initially produced, which resides in the culture, was depleted as the headspace was continuously sampled into the SIFT-MS instrument. This speculation is not the major point of this experiment; rather, it is to demonstrate that MDA can now be detected and quantified in the gas phase in real time by SIFT-MS obviating derivatisation that can disturb the biological system.

\section{Concluding remarks}

The SIFT-MS analytical method has often been shown to be a valuable and accurate method for ambient analysis of trace compounds in humid air, including exhaled breath. This requires that the ion chemistry underpinning the analyses is well understood, and in this regard, special attention needs to be given to some compounds because of the peculiar aspects of their reactions with ions in the gas phase. This is especially so when attempting to analyse unstable molecules such as the biologically important MDA, the focus of the present study. Thus, following a detailed study of the relevant ion chemistry, we have shown that MDA can now be directly detected and quantified by SIFT-MS in real time in humid air like the headspace of biological fluids such as cell and tissue cultures, avoiding the complications associated with molecular derivatisation of the MDA. An additional contribution made by this study is the provision of the EI mass spectra of MDA, which facilitates the direct GC/MS analysis of MDA molecules

following SPME collection. These advances open the way to detailed investigations of peroxidation processes in biology.

\section{Acknowledgements}

We gratefully acknowledge funding from Grant Agency of the Czech Republic project No 1415771P. We also thank to Dr. Marek Cebecauer for assistance with the cell cultures. 
Table 1. SIFT-MS kinetics library entries ${ }^{\mathrm{a}}$ for the determination of the concentrations of MDA in humid samples using $\mathrm{H}_{3} \mathrm{O}^{+}, \mathrm{NO}^{+}$and $\mathrm{O}_{2}{ }^{+\bullet}$ reagent ions at $300 \mathrm{~K}$

\begin{tabular}{cccc}
\hline MDA $\left(\mathbf{H}_{3} \mathbf{O}^{+}\right)$ & MDA $\left(\mathbf{O}_{2}{ }^{+\bullet}\right)$ & \multicolumn{2}{c}{$\mathbf{M D A}\left(\mathbf{N O}^{+}\right)$} \\
\hline 4 precursors & 1 precursor & 3 precursors & 3 precursors \\
$195.7 \mathrm{e}-91.0$ & $324.7 \mathrm{e}-91.0$ & $304.8 \mathrm{e}-91.0$ & $304.8 \mathrm{e}-91.0$ \\
$374.5 \mathrm{e}-91.0$ & 4 products & $484.1 \mathrm{e}-91.0$ & $484.1 \mathrm{e}-96.0$ \\
$554.0 \mathrm{e}-91.0$ & 721 & $663.8 \mathrm{e}-91.0$ & $663.8 \mathrm{e}-96.0$ \\
73 3.7e-9 1.0 & 901 & 4 products & 2 products \\
1 product & 1081 & 711 & 892.5 \\
1095.0 & 1261 & 891 & 1022.0 \\
& & 1021 & \\
& & 1201 & \\
\hline
\end{tabular}

${ }^{\text {a }}$ Each entry contains a list of precursor ion $\mathrm{m} / \mathrm{z}$ values each followed by the rate coefficient in units of $\mathrm{cm}^{3} \mathrm{~s}^{-1}$. Then a list of product ion $\mathrm{m} / \mathrm{z}$ values is given. At the end of each row a coefficient is given that is used to multiply the count rate measured at the given $\mathrm{m} / \mathrm{z}$ which accounts for any excluded analyte ions; see the text for further explanation. 


\section{References.}

1. M. E. Haberland, D. Fong, L. Cheng. Malondialdehyde-Altered Protein Occurs in Atheroma of Watanabe Heritable Hyperlipidemic Rabbits. Science 1988, 241, 215.

2. P. Holvoet, G. Perez, Z. Zhao, E. Brouwers, H. Bernar, D. Collen. MalondialdehydeModified Low-Density Lipoproteins in Patients with Atherosclerotic Disease. Journal of Clinical Investigation 1995, 95, 2611.

3. C. C. Benz, C. Yau. Ageing, oxidative stress and cancer: paradigms in parallax. Nat. Rev. Cancer 2008, 8, 875.

4. A. R. Bitla, E. P. Reddy, K. Sambasivaih, M. M. Suchitra, V. S. Reddy, P. V. L. N. S. Rao. Evaluation of Plasma Malondialdehyde as a Biomarker in Patients with Carcinoma of stomach. BioMed. Res-India 2011, 22, 63.

5. K. Young, D. Benissan-Messan, M. J. Duryee, D. Anderson, L. Caplan, L. A. Davis, H. Sayles, C. D. Hunter, L. W. Klassen, J. R. O'Dell, T. R. Mikuls, G. M. Thiele. Antibody To Malondialdehyde-Acetaldehyde Adducts (MAA) Is a Biomarker Of Inflammation and Is Correlated With The Disease Activity In Rheumatoid. Arthritis Rheum 2013, 65, S962.

6. Z. Singh, I. P. Karthigesu, P. Singh, R. Kaur. Use of Malondialdehyde as a Biomarker for Assessing Oxidative Stress in Different Disease Pathologies: a Review. Iran J. Public Health 2014, 43, 7.

7. D. Grotto, L. S. Maria, J. Valentini, C. Paniz, G. Schmitt, S. C. Garcia, V. J. Pomblum, J. B. T. Rocha, M. Farina. Importance of the Lipid Peroxidation Biomarkers and Methodological Aspects for Malondialdehyde Quantification. Quim Nova 2009, 32, 169.

8. K. Dryahina, V. Pospisilova, K. Sovova, V. Shestivska, J. Kubista, A. Spesyvyi, F. Pehal, J. Turzikova, J. Votruba, P. Spanel. Exhaled breath concentrations of acetic acid vapour in gastro-esophageal reflux disease. J. Breath Res. 2014, 8.

9. S. Kumar, J. Huang, N. Abbassi-Ghadi, H. Mackenzie, J. Hoare, P. Španěl, D. Smith, G. B. Hanna. SIFT-MS analysis of exhaled breath for volatile organic profiling of oesophago-gastric cancer. Br. J. Surg. 2014, 101, 17.

10. K. Dryahina, P. Španěl, V. Pospisilova, K. Sovova, L. Hrdlicka, N. Machkova, M. Lukas, D. Smith. Quantification of pentane in exhaled breath, a potential biomarker of bowel disease, using selected ion flow tube mass spectrometry. Rapid Commun. Mass Spectrom. 2013, 27, 1983.

11. D. Smith, T. W. E. Chippendale, K. Dryahina, P. Španěl. SIFT-MS Analysis of NoseExhaled Breath; Mouth Contamination and the Influence of Exercise. Current Analytical Chemistry 2013, 9, 565.

12. T. W. E. Chippendale, F. J. Gilchrist, P. Španěl, A. Alcock, W. Lenney, D. Smith. Quantification by SIFT-MS of volatile compounds emitted by Aspergillus fumigatus cultures and in co-culture with Pseudomonas aeruginosa, Staphylococcus aureus and Streptococcus pneumoniae. Analytical Methods 2014, 6, 8154.

13. V. Shestivska, P. Španěl, K. Dryahina, K. Sovová, D. Smith, M. Musilek, A. Nemec. Variability in the concentrations of volatile metabolites emitted by genotypically different strains of Pseudomonas aeruginosa. J. Appl. Microbiol. 2012, 113, 701.

14. A. V. Rutter, T. W. E. Chippendale, Y. Yang, P. Španěl, D. Smith, J. Sule-Suso. Quantification by SIFT-MS of acetaldehyde released by lung cells in a 3D model. Analyst 2013, 138, 91. 
15. D. Smith, T. S. Wang, J. Sule-Suso, P. Španěl, A. El Haj. Quantification of acetaldehyde released by lung cancer cells in vitro using selected ion flow tube mass spectrometry. Rapid Commun. Mass Spectrom. 2003, 17, 845.

16. P. Španěl, D. Smith, T. A. Holland, W. Al Singary, J. B. Elder. Analysis of formaldehyde in the headspace of urine from bladder and prostate cancer patients using selected ion flow tube mass spectrometry. Rapid Commun. Mass Spectrom. 1999, 13, 1354.

17. P. Španěl, D. Smith. Quantification of hydrogen sulphide in humid air by selected ion flow tube mass spectrometry. Rapid Commun. Mass Spectrom. 2000, 14, 1136.

18. P. Španěl, T. S. Wang, D. Smith. Quantification of hydrogen cyanide in humid air by selected ion flow tube mass spectrometry. Rapid Commun. Mass Spectrom. 2004, 18, 1869.

19. K. Dryahina, D. Smith, P. Španěl. Quantification of methane in humid air and exhaled breath using selected ion flow tube mass spectrometry. Rapid Commun. Mass Spectrom. 2010, 24, 1296.

20. H. Esterbauer, K. H. Cheeseman. Determination of aldehydic lipid peroxidation products: malonaldehyde and 4-hydroxynonenal. Methods Enzymol 1990, 186, 407.

21. H. A. H. M. A. El-Aal, Lipid Peroxidation End-Products as a Key of Oxidative Stress: Effect of Antioxidant on Their Production and Transfer of Free Radicals. Lipid Peroxidation. 2012.

22. L. J. Marnett, M. A. Tuttle. Comparison of the Mutagenicities of Malondialdehyde and the Side Products Formed during Its Chemical Synthesis. Cancer research 1980, 40, 276.

23. A. L. Spirlandeli, R. Deminice, A. A. Jordao. Plasma Malondialdehyde as Biomarker of Lipid Peroxidation: Effects of Acute Exercise. International Journal of Sports Medicine 2014, 35, 14.

24. C. Fucile, V. Marini, M. L. Zuccoli, S. Leone, L. Robbiano, A. Martelli, F. Mattioli. HPLC Determination of Malondialdehyde as Biomarker for Oxidative Stress: Application in Patients with Alcohol Dependence. Clin Lab 2013, 59, 837.

25. S. Zelzer, R. Oberreither, C. Bernecker, I. Stelzer, M. Truschnig-Wilders, G. Fauler. Measurement of total and free malondialdehyde by gas-chromatography mass spectrometry - comparison with high-performance liquid chromatography methology. Free Radical Research 2013, 47, 651.

26. G. Cighetti, S. Debiasi, R. Paroni, P. Allevi. Free and total malondialdehyde assessment in biological matrices by gas chromatography mass spectrometry: What is needed for an accurate detection. Anal. Biochem. 1999, 266, 222.

27. H.-S. Shin, D.-G. Jung. Sensitive Analysis of Malondialdehyde in Human Urine by Derivatization with Pentafluorophenylhydrazine then Headspace GC-MS. Chromatographia 2009, 70, 899.

28. C. R. Wade, P. G. Jackson, A. M. Vanrij. Quantitation of Malondialdehyde (Mda) in Plasma, by Ion-Pairing Reverse Phase High-Performance Liquid-Chromatography. Biochem Med. Metab B 1985, 33, 291.

29. I. Romieu, A. Barraza-Villarreal, C. Escamilla-Nunez, A. C. Almstrand, D. DiazSanchez, P. D. Sly, A. C. Olin. Exhaled breath malondialdehyde as a marker of effect of exposure to air pollution in children with asthma. Journal of Allergy and Clinical Immunology 2008, 121, 903.

30. J. C. Gong, T. Zhu, H. Kipen, G. F. Wang, M. Hu, P. Ohman-Strickland, S. E. Lu, L. Zhang, Y. D. Wang, P. Zhu, D. Q. Rich, S. R. Diehl, W. Huang, J. F. Zhang. 
Malondialdehyde in exhaled breath condensate and urine as a biomarker of air pollution induced oxidative stress. J. Expo Sci Env Epid 2013, 23, 322.

31. H. S. Shin. Determination of malondialdehyde in human blood by headspace-solid phase micro-extraction gas chromatography-mass spectrometry after derivatization with 2,2,2trifluoroethylhydrazine. Journal of Chromatography B-Analytical Technologies in the Biomedical and Life Sciences 2009, 877, 3707.

32. M. A. E. Larstad, K. Toren, B. Bake, A. C. Olin. Determination of ethane, pentane and isoprene in exhaled air - effects of breath-holding, flow rate and purified air. Acta Physiol 2007, 189, 87.

33. A. Olivares, K. Dryahina, J. L. Navarro, D. Smith, P. Španěl, M. Flores. SPME-GC-MS versus Selected Ion Flow Tube Mass Spectrometry (SIFT-MS) Analyses for the Study of Volatile Compound Generation and Oxidation Status during Dry Fermented Sausage Processing. Journal of Agricultural and Food Chemistry 2011, 59, 1931.

34. P. Španěl, J. M. Van Doren, D. Smith. A selected ion flow tube study of the reactions of $\mathrm{H}_{3} \mathrm{O}^{+}, \mathrm{NO}^{+}$, and $\mathrm{O}_{2}{ }^{+}$with saturated and unsaturated aldehydes and subsequent hydration of the product ions. Int. J. Mass Spectrom. 2002, 213, 163.

35. B. M. Ross, S. Puukila, I. Malik, S. Babay, M. Lecours, A. Agostino, T. Wondimu, N. Khaper. The Use of SIFT-MS to Investigate Headspace Aldehydes as Markers of Lipid Peroxidation. Current Analytical Chemistry 2013, 9, 600.

36. P. Španěl, D. Smith. Advances in On-line Absolute Trace Gas Analysis by SIFT-MS. Current Analytical Chemistry 2013, 9, 525.

37. P. Španěl, D. Smith. Influence of water vapour on selected ion flow tube mass spectrometric analyses of trace gases in humid air and breath. Rapid Commun. Mass Spectrom. 2000, 14, 1898.

38. K. Sovová, K. Dryahina, P. Španěl. Selected ion flow tube (SIFT) studies of the reactions of $\mathrm{H}_{3} \mathrm{O}^{+}, \mathrm{NO}^{+}$and $\mathrm{O}_{2}{ }^{+\bullet}$ with six volatile phytogenic esters. Int. J. Mass Spectrom. 2011, 300,31 .

39. D. Smith, T. W. E. Chippendale, P. Španěl. Reactions of the selected ion flow tube mass spectrometry reagent ions $\mathrm{H} 3 \mathrm{O}+$ and $\mathrm{NO}+$ with a series of volatile aldehydes of biogenic significance. Rapid Commun. Mass Spectrom. 2014, 28, 1917.

40. P. Španěl, K. Dryahina, D. Smith. A general method for the calculation of absolute trace gas concentrations in air and breath from selected ion flow tube mass spectrometry data. Int. J. Mass Spectrom. 2006, 249, 230.

41. D. Smith, N. G. Adams. The selected ion flow tube(SIFT): studies of ion-neutral reactions. Advances in Atomic and Molecular Physics 1988, 24, 1.

42. D. Smith, P. Španěl. Selected ion flow tube mass spectrometry (SIFT-MS) for on-line trace gas analysis. Mass Spectrom. Rev. 2005, 24, 661.

43. D. Smith, P. Španěl, Swarm techniques, in Atomic, Molecular, and Optical Physics: Charged Particles, Volume 29A (Experimental Methods in the Physical Sciences), F.B. Dunning and R.G. Hulet, Editors. 1995, Academic Press: New York. pp. 273.

44. G. E. Moore, R. E. Gerner, H. A. Franklin. Culture of normal human leukocytes. Journal of the American Medical Association 1967, 199, 519.

45. P. Mochalski, K. Unterkofler, P. Španěl, D. Smith, A. Amann. Product ion distributions for the reactions of $\mathrm{NO}+$ with some physiologically significant aldehydes obtained using a SRI-TOF-MS instrument. Int. J. Mass Spectrom. 2014, 363, 23. 
46. P. Španěl, D. Smith. On-line measurement of the absolute humidity of air, breath and liquid headspace samples by selected ion flow tube mass spectrometry. Rapid Commun. Mass Spectrom. 2001, 15, 563.

47. P. Španěl, D. Smith. Influence of weakly bound adduct ions on breath trace gas analysis by selected ion flow tube mass spectrometry (SIFT-MS). Int. J. Mass Spectrom. 2009, $280,128$.

48. G. Bouchoux, J. Y. Salpin, D. Leblanc. A relationship between the kinetics and thermochemistry of proton transfer reactions in the gas phase. Int. J. Mass Spectrom. Ion Process. 1996, 153, 37.

49. E. Hunter, S. Lias. Evaluated gas phase basicities and proton affinities of molecules: An update. J. Phys. Chem. Ref. Data 1998, 27, 413.

50. T. Su, W. J. Chesnavich. Parametrization of the ion-polar molecule collision rate-constant by trajectory calculations. J. Chem. Phys. 1982, 76, 5183.

51. K. J. Miller, J. A. Savchik. New empirical-method to calculate average molecular polarizabilities. J. Am. Chem. Soc. 1979, 101, 7206.

52. P. Španěl, Y. F. Ji, D. Smith. SIFT studies of the reactions of $\mathrm{H}_{3} \mathrm{O}^{+}, \mathrm{NO}^{+}$and $\mathrm{O}_{2}{ }^{+}$with a series of aldehydes and ketones. Int. J. Mass Spectrom. 1997, 165, 25.

53. D. J. Giard, S. A. Aaronson, G. J. Todaro, P. Arnstein, J. H. Kersey, H. Dosik, W. P. Parks. In-Vitro Cultivation of Human Tumors - Establishment of Cell Lines Derived from a Series of Solid Tumors. J. Natl Cancer I 1973, 51, 1417.

54. J. A. Kazzaz, J. Xu, T. A. Palaia, L. Mantell, A. M. Fein, S. Horowitz. Cellular oxygen toxicity - Oxidant injury without apoptosis. J Biol. Chem. 1996, 271, 15182.

55. J. Devries, C. N. Verboom. Effects of Scavengers of Superoxide Radicals, HydrogenPeroxide, Singlet Oxygen and Hydroxyl Radicals on Malondialdehyde Generation from Arachidonic-Acid by Bovine Seminal-Vesicle Microsomes. Experientia 1980, 36, 1339.

56. R. D. Levy, M. M. J. Oosthuizen, E. Degiannis, H. Lambrechts. Elevated reversible and irreversible lipid peroxidation in human oesophageal cancer. Anticancer Research 1998, $18,1325$. 


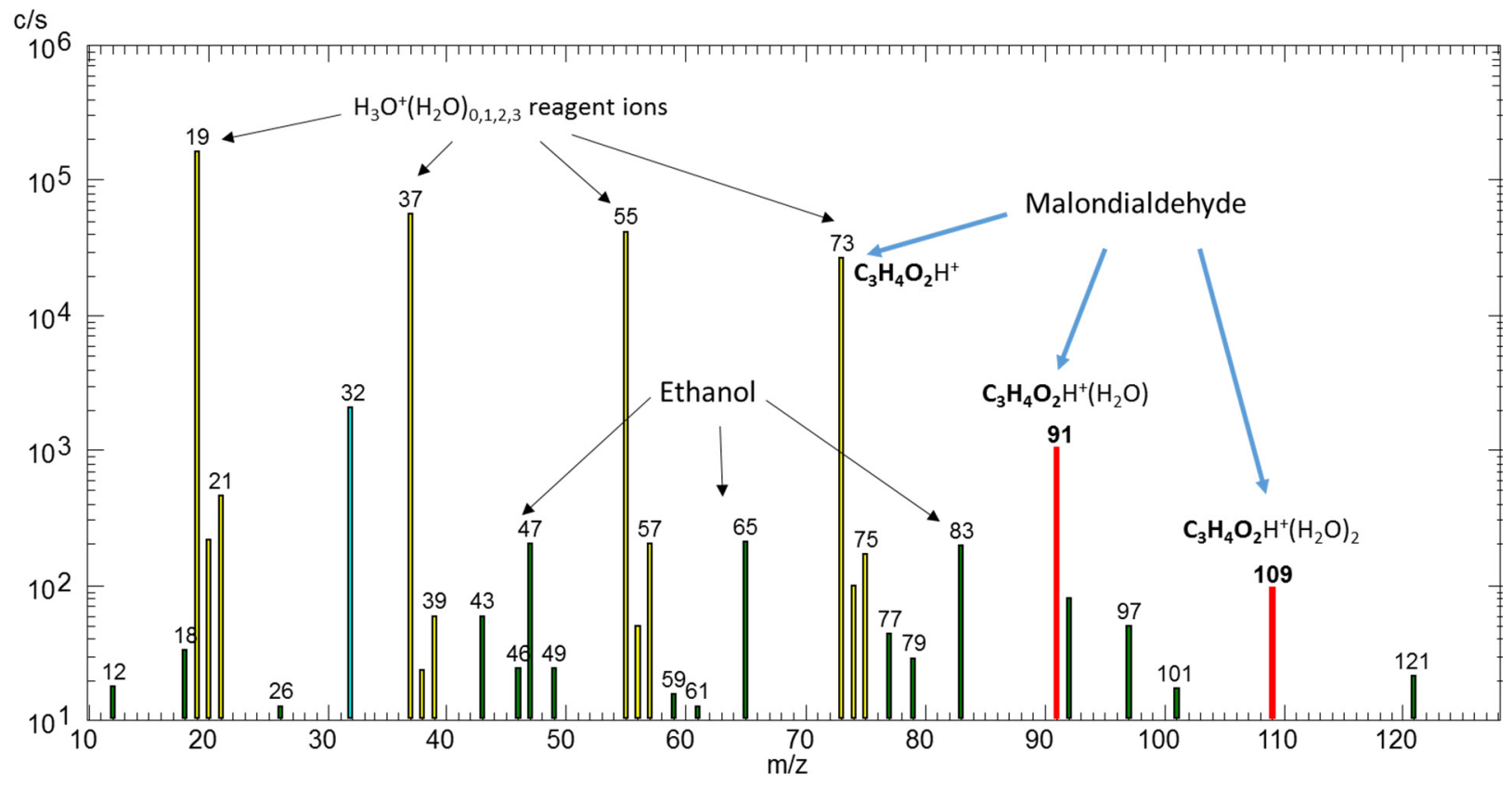

Fig.1 Full scan spectrum obtained when the humid headspace of the MDA solution is flowed into the helium carrier gas $/ \mathrm{H}_{3} \mathrm{O}^{+}$ion swarm of the SIFT instrument showing the product ions at $m / z 91$ that comprise $\mathrm{H}_{3} \mathrm{O}^{+}\left(\mathrm{H}_{2} \mathrm{O}\right)_{4}$ and $\operatorname{MDAH}^{+}\left(\mathrm{H}_{2} \mathrm{O}\right)$ ions, and $\mathrm{MDAH}^{+}\left(\mathrm{H}_{2} \mathrm{O}\right)_{2}$ ions and at $m / z$ 109 ; see text for further explanation. 


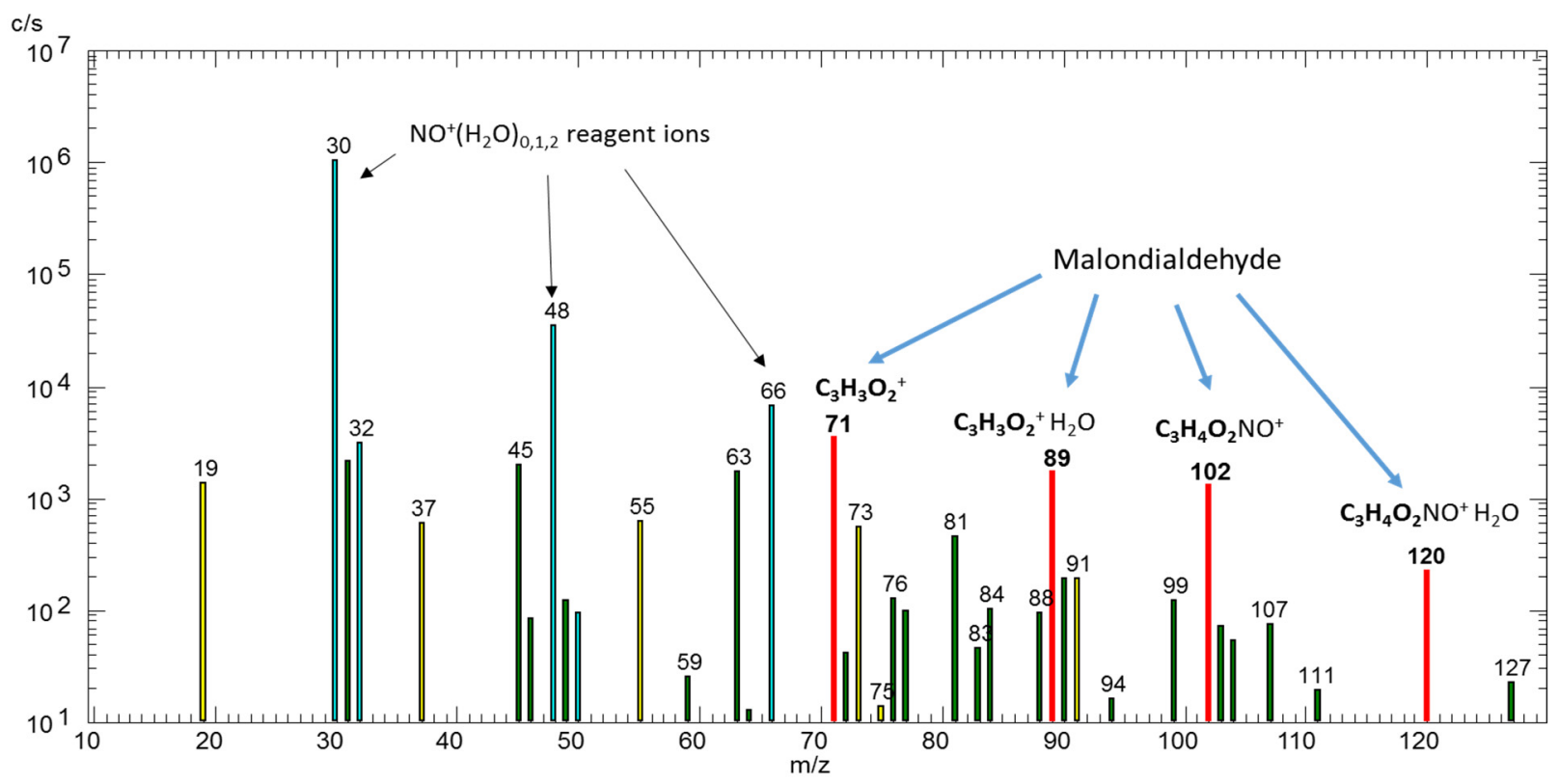

Fig.2 Full scan spectrum obtained when the humid headspace of the MDA solution is flowed into the helium carrier gas/ $\mathrm{NO}^{+}$ion swarm of the SIFT instrument showing four characteristic product ions at $m / z 71,89,102,120$ due to MDA; see text for further explanation. 


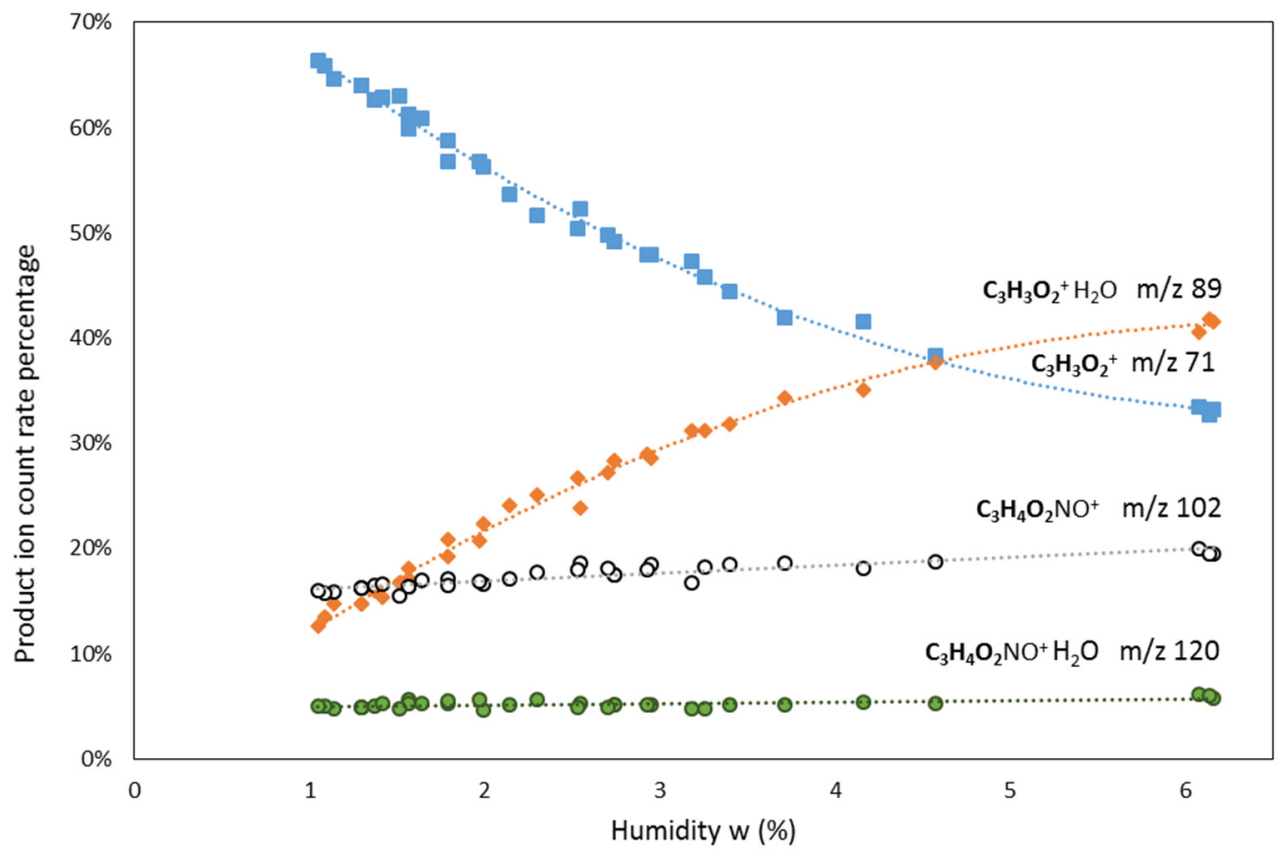

Fig.3 Relative intensities of the product ions MDA- $\mathrm{H}^{-}\left(\mathrm{C}_{3} \mathrm{H}_{3} \mathrm{O}_{2}{ }^{+}\right), \mathrm{NO}^{+} \mathrm{MDA}\left(\mathrm{C}_{3} \mathrm{H}_{4} \mathrm{O}_{2} \mathrm{NO}^{+}\right)$and their monohydrates as a function on the sample humidity within the range $1 \%$ to $6 \%$ observed by SIFT using $\mathrm{NO}^{+}$precursor ions. 


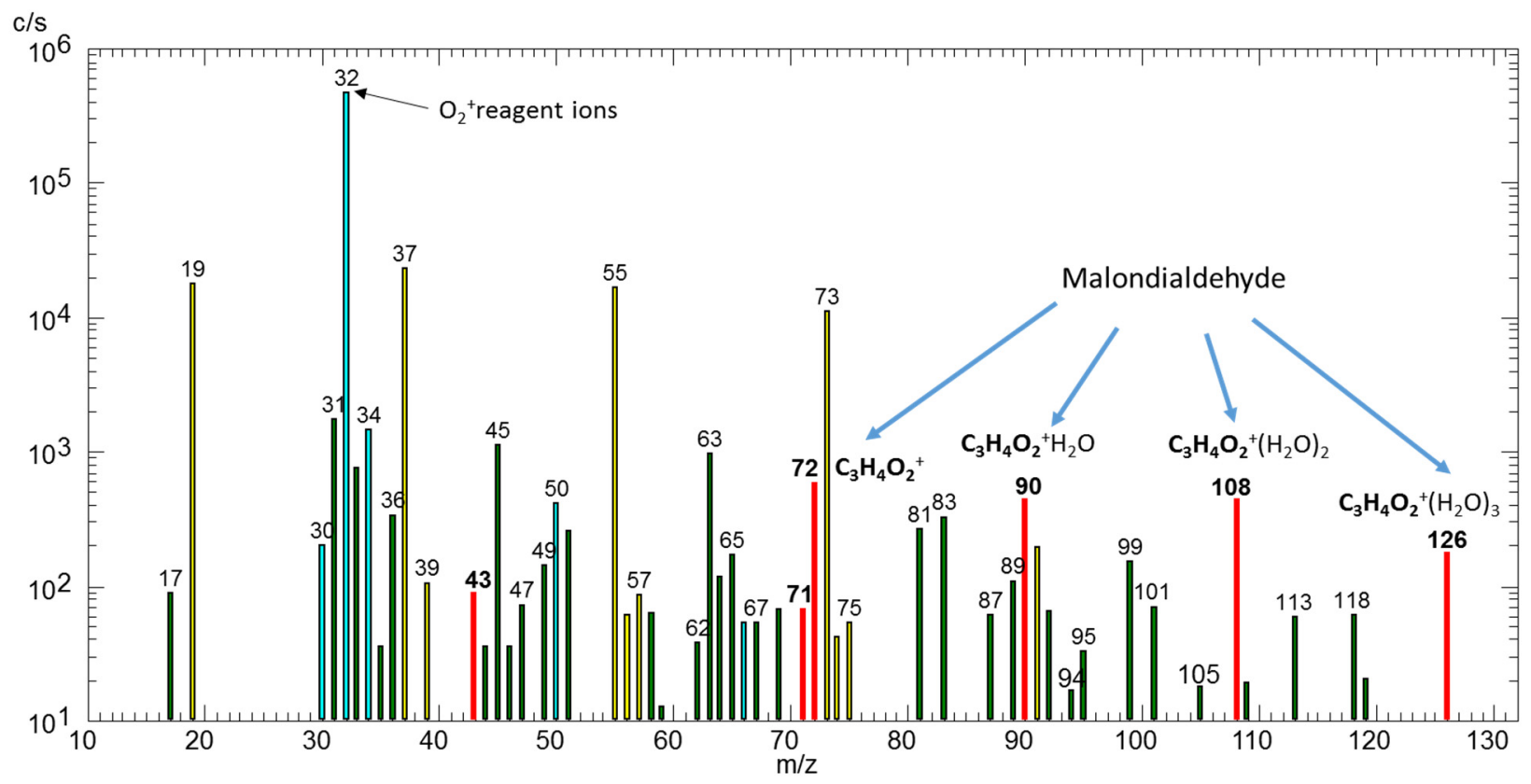

Fig.4 Full scan spectrum obtained when the humid headspace of the MDA solution is flowed into the helium carrier gas $/ \mathrm{O}_{2}{ }^{+}$ion swarm of the SIFT instrument showing product ions at $\mathrm{m} / \mathrm{z}$ $43,71,72,90,108$ and 126; see text for further explanation. 


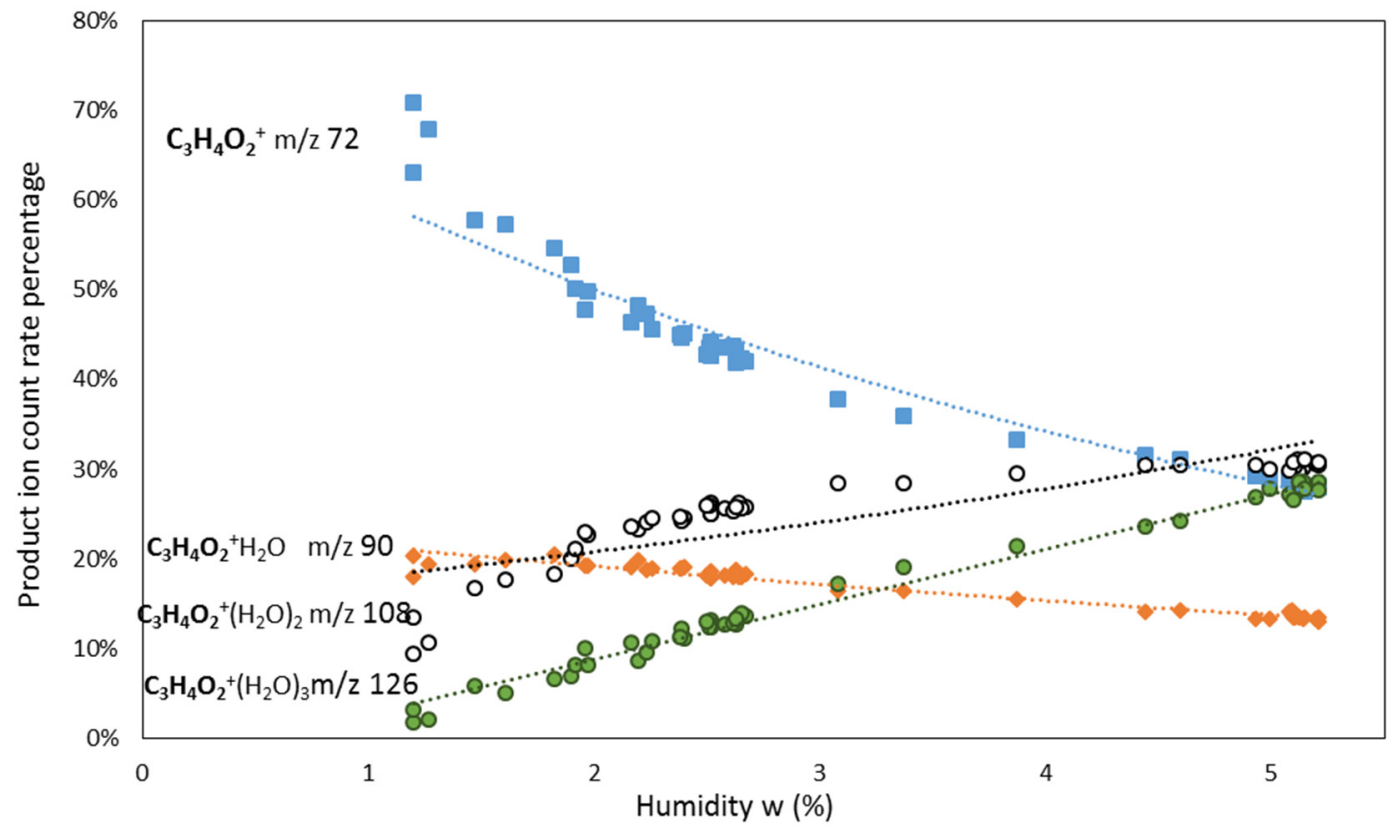

Fig.5 Relative intensities of the product parent cation $\mathrm{MDA}+\left(\mathrm{C}_{3} \mathrm{H}_{4} \mathrm{O}_{2+}\right)$ and its hydrates as a function on the sample humidity within the range $1 \%$ to $5 \%$ observed by SIFT using $\mathrm{O}_{2}^{+\cdot}$ precursor ions. 

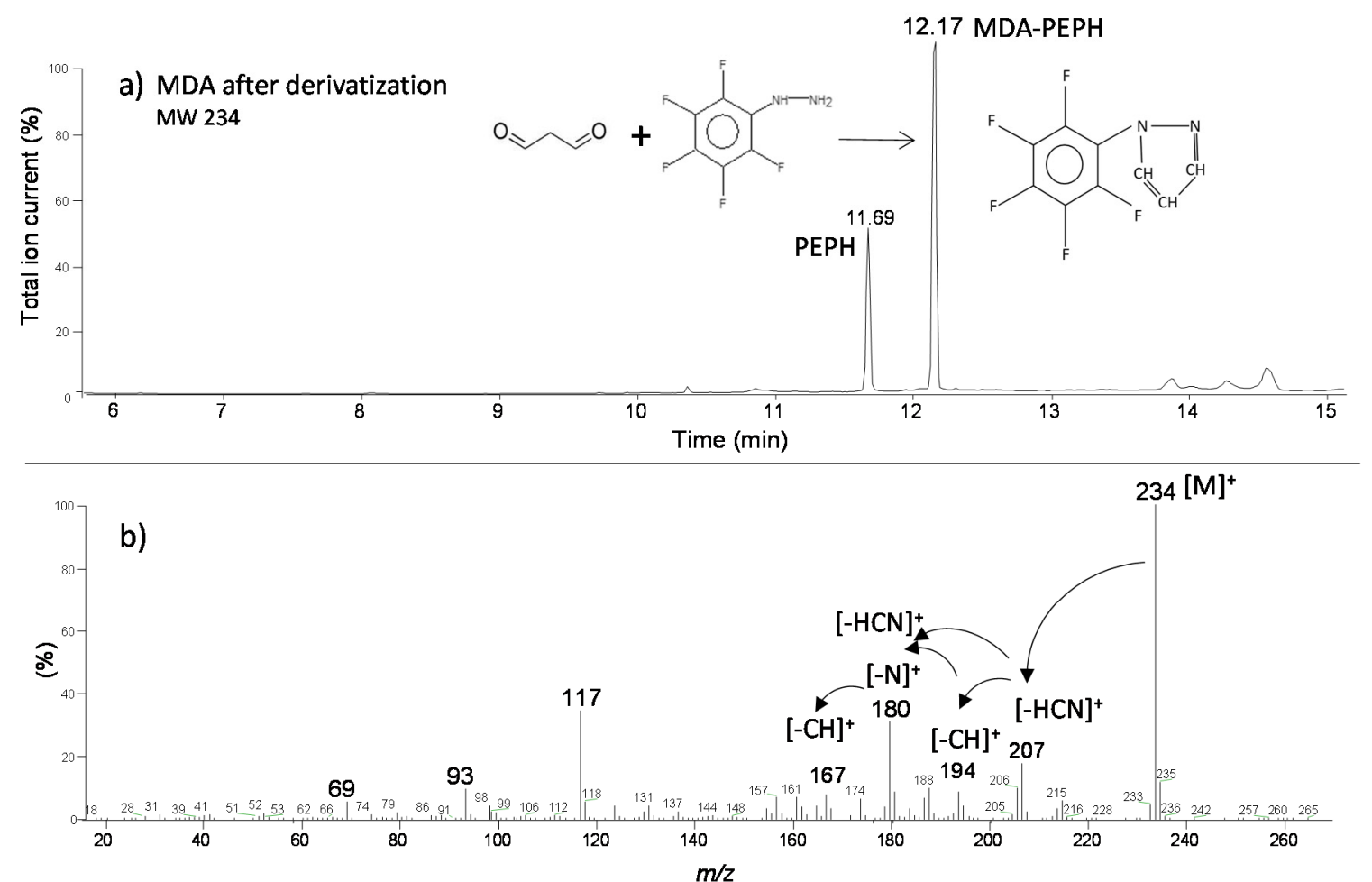

Fig. 6 a) SPME/GC-MS chromatogram showing the peak at an elution time of 12.17 min due to the derivative MDA-PFPH (structure shown) and b) and the EI mass spectrum obtained for the MDA-PFPH showing the molecular ion an $\mathrm{m} / \mathrm{z}$ of 234 and several fragments. 

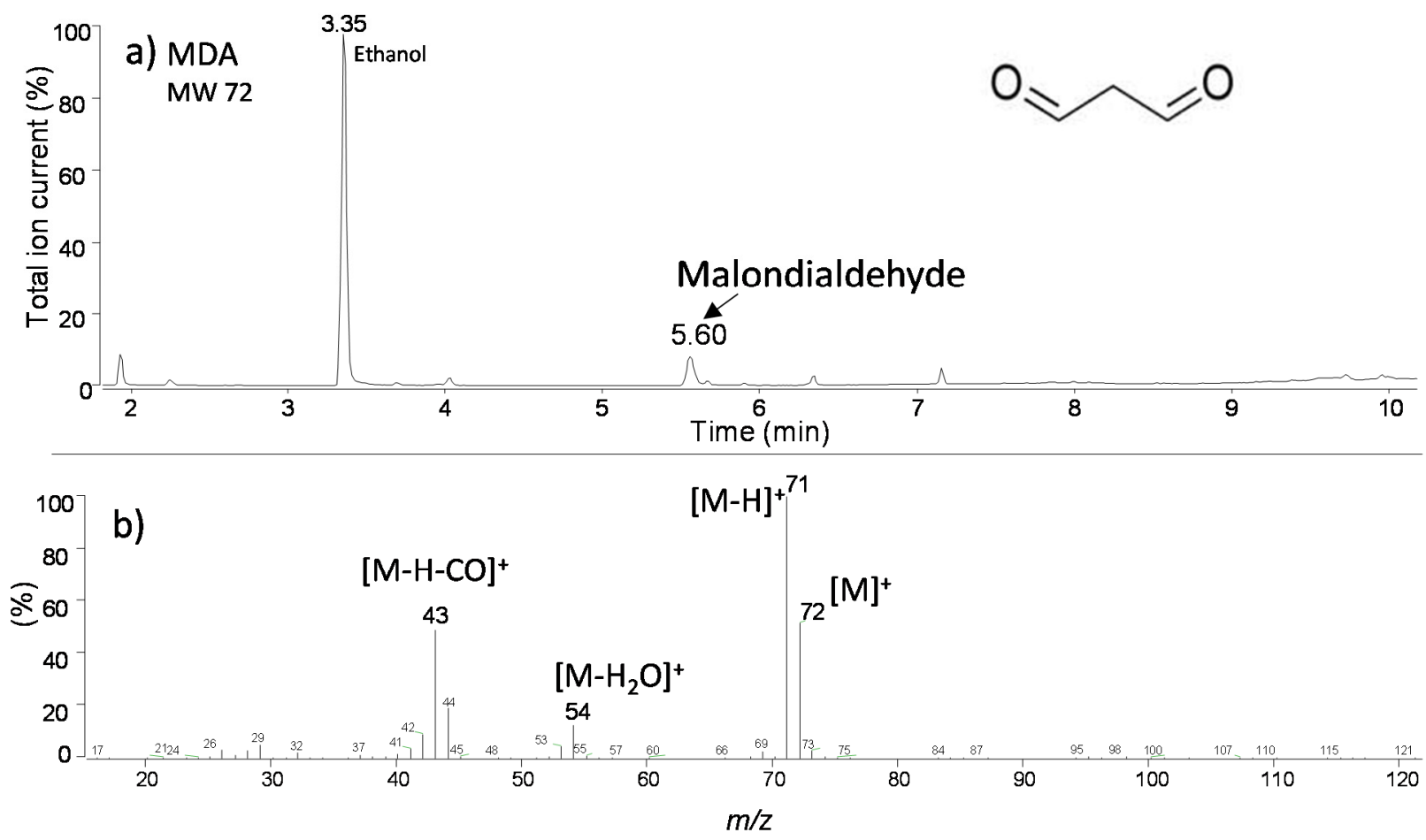

Fig.7. SPME/GC-MS chromatogram (a) and EI mass spectrum (b) obtained for the extraction and analysis of the headspace of the standard aqueous solution of MDA $(300 \mathrm{mg} / \mathrm{L})$. The peak at $5.60 \mathrm{~min}$ is due to free MDA. 

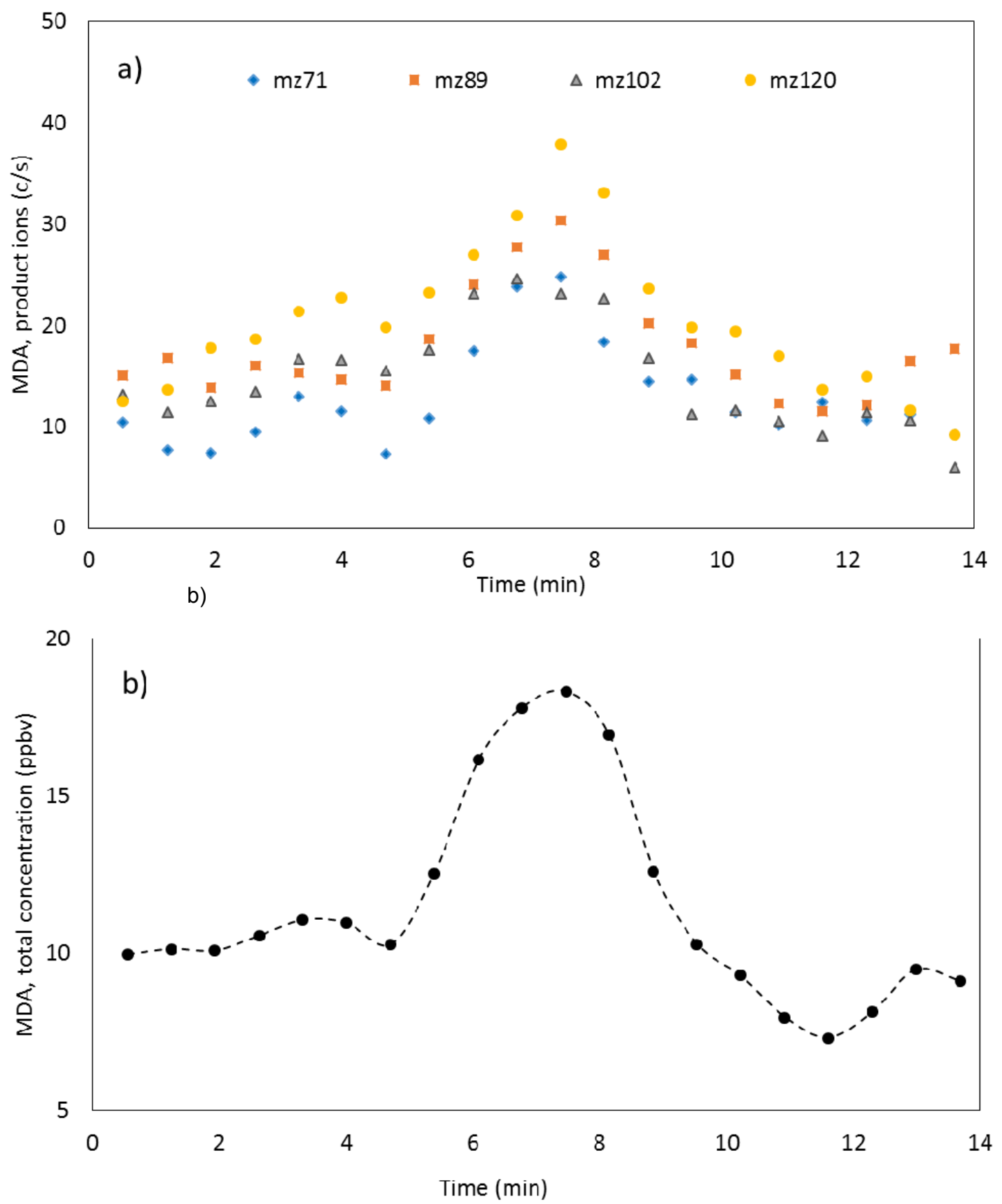

Fig.8 SIFT-MS real time quantification of MDA in the headspace of a culture of lung adenocarcinoma cancer cells (A549) after $20 \mathrm{mM}$ of $\mathrm{H}_{2} \mathrm{O}_{2}$ has been added at time 0 at a culture temperature of $38^{\circ} \mathrm{C}$. a) shows the product ion count rates using $\mathrm{NO}^{+}$precursor ions (count rate $500000 \mathrm{c} / \mathrm{s}$ ) and b) shows the gas phase quantification of MDA in parts-perbillion by volume, ppbv as calculated from the count rate of product ions at $\mathrm{m} / \mathrm{z} 71,89$ and 102. 